\title{
A expansão da soja no município de Jaguarão/RS: análise das percepções através da abordagem narrativa
}

\author{
The expansion of soy in the county of Jaguarão/RS: analysis of perceptions \\ through the narrative approach \\ Monica Nardini da Silva ${ }^{1}$ (D), Flávio Sacco dos Anjos $^{1}$ (1) \\ ${ }^{1}$ Universidade Federal de Pelotas (UFPel), Pelotas (RS), Brasil. E-mails: moninardini@yahoo.com.br; saccodosanjos@gmail.com
}

Como citar: Silva, M. N., \& Sacco dos Anjos, F. (2020). A expansão da soja no município de Jaguarão/RS: análise das percepções através da abordagem narrativa. Revista de Economia e Sociologia Rural, 58(3), e213748. https://doi.org/10.1590/18069479.2020 .213748

Resumo: Situado no extremo sul do Brasil, o município de Jaguarão tem na produção de ovinos e de bovinos, em regime de criação extensiva, duas tradicionais vocações agropecuárias. Não obstante, desde os últimos dez anos constata-se, em seu interior, a exemplo do que ocorre em outras localidades pertencentes ao bioma Pampa, uma transformação importante do ponto de vista social, paisagístico e ambiental. Ela está relacionada aos efeitos produzidos pela expansão da área cultivada de soja, fato que supôs a conversão de aproximadamente 37 mil hectares, predominantemente de pastos nativos, em áreas dedicadas a essa cultura. Neste estudo nossa atenção envolveu dois grandes objetivos. O primeiro foi analisar os impactos socioambientais da expansão da soja. O segundo foi refletir sobre a necessidade de políticas públicas para regulamentar o plantio dessa cultura em Jaguarão. Em ambos os casos nos valemos da abordagem narrativa realizada a partir de entrevistas com produtores rurais e outros atores locais. Constatou-se a existência de duas grandes orientações narrativas. De um lado, a posição de atores locais que argumentam a necessidade de uma política reguladora, de outro, os que se posicionam contra, alegando que tal cultivo traz desenvolvimento para Jaguarão e para a região.

Palavras-chave: política pública, impactos socioambientais, abordagem narrativa, soja, bioma Pampa.

\begin{abstract}
Located in the extreme south of Brazil, the town of Jaguarão shows, in an extensive regime, two traditional livestock vocations: sheep and cattle production. Nevertheless, during the last ten years, there has been an important transformation from a social, landscape, and environmental point of view, as in other places in the Pampa Biome. It is related to the effects produced by the expansion of the cultivated area with the soybean crop, a fact that maybe the reason for the conversion of approximately 37 thousand hectares, predominantly native pastures, in areas dedicated to this culture. In this study, our attention involved two major objectives. The first one was to analyze the socio-environmental impacts of soybean expansion. The second was to reflect on the need for public policies to regulate the planting of this cultivation in Jaguarão. In both cases, we used the narrative approach conducted from interviews with rural producers and other local actors. The existence of two great narrative orientations was verified. On the one hand, the position of actors who argue the need for regulatory policy, on the other, the actors who oppose, claiming that soybean cultivation brings development to Jaguarão and the region.
\end{abstract}

Keywords: public policy, social and environmental impacts, narrative approach, soy, Pampa biome.

\section{Introdução}

Entre as décadas de 1960 e 1980 o Brasil vivenciou o auge do que se conhece como processo de modernização "conservadora" da agricultura (Brum, 1987; Sacco dos Anjos, 2003). A expressão destacada tem a ver com o fato de que esse país optou por alterar a base técnica, via introdução dos insumos modernos (sementes melhoradas, máquinas agrícolas, adubos sintéticos e agrotóxicos) sem promover alterações sobre a estrutura 
fundiária, ou seja, sem realizar a reforma agrária almejada pelas organizações de trabalhadores rurais e movimentos sociais de luta pela terra.

Nesse período, as políticas de crédito, preços mínimos, pesquisa, armazenamento, transporte e assistência técnica estiveram essencialmente direcionadas para as culturas voltadas para a exportação e/ou para assegurar a substituição de importações. Em boa medida o Brasil reproduziu o modelo que já havia sido implantado na década anterior nos países da Europa e América do Norte, dentro de um contexto mais amplo de mudanças denominado "revolução verde", que igualmente se espraiou pela Ásia e demais países da América Latina.

A literatura sobre o tema apresenta dois grandes ângulos de abordagem. De um lado estão os autores que se detêm apenas nas mudanças técnicas, de outro, os que analisam as transformações que o fenômeno ocasionou sobre as relações sociais de produção e/ou sobre a agricultura e o mundo rural como um todo. O fato é que a agricultura brasileira passou por uma grande transformação, que implicou em diversas mudanças no meio rural.

O grande objetivo era aumentar a produção agrícola através do uso intensivo de capital e tecnologia. Esse modelo, que teve o Estado como grande promotor e principal financiador, resultou em um considerável incremento na produtividade e na expansão da fronteira agrícola. Não obstante, privilegiou as culturas voltadas à exportação, os grandes produtores e as regiões Sul, Sudeste e Centro-Oeste. No curso desse processo, acentuaram-se as desigualdades sociais e os danos ambientais. Niederle (2007) lembra que esse padrão foi marcado pela dependência exógena, com a crescente externalização dos processos produtivos, aumentando a dependência tecnológica e reduzindo o grau de autonomia dos agricultores.

Ao estudar as mudanças que a modernização da agricultura ocasionou sobre as condições de existência de famílias rurais do extremo sul do Brasil, Sacco dos Anjos et al. (2010) constataram outros desdobramentos, entre os quais o incremento à intensificação e à especialização produtiva. Nesse sentido, ao dependerem do resultado econômico de uma única cultura ou criação, as famílias tendem a abandonar a produção de autoconsumo, aumentando, ainda mais, o grau de vulnerabilidade e de incerteza.

Esse processo resulta, como destacado pelos autores, na perda da autonomia das famílias, que passam a uma posição subordinada aos mercados e às imposições das grandes empresas. Com isso, "no curso das transformações operadas a partir da modernização da agricultura houve a eliminação de muitas explorações familiares que se mostravam incapazes de incorporar as inovações tecnológicas e o novo modo de produzir" (Sacco dos Anjos et al., 2010, p. 120). Nesse sentido, Conterato (2004), ao estudar o processo de mercantilização da região do Alto Uruguai, identificou uma redução média de 17,2\% da população rural dos municípios daquela região no período de 1970 a 2000. Esse fenômeno não implica somente em mudanças na produção, representa também a transformação de um modo de vida. Ellis (1999) define modo de vida como: as atividades, ativos e acessos, que juntos definem os meios de vida da família ou indivíduo. “Enfim, modo de vida é composto por um conjunto de alternativas de ações e estratégias" (Ribeiro, 2009, p. 80).

Outro fenômeno associado à modernização refere-se à expulsão da mão de obra devido ao incremento da mecanização das atividades produtivas. Sacco dos Anjos \& Caldas (2007) pesquisaram esse declínio da ocupação da força de trabalho rural e destacaram que, de acordo com essa lógica de desenvolvimento, a eficiência econômica está associada à redução da mão de obra ocupada no processo produtivo. Segundo os autores, "em 1981 a população ocupada em atividades agrícolas representava $77,5 \%$ do total de ocupados no espaço rural, em 1999, esse conjunto se viu reduzido a 68,4\%" (Sacco dos Anjos \& Caldas, 2007, p. 311).

No contexto da modernização houve também a expansão da fronteira agrícola brasileira através da incorporação de grandes áreas do Brasil central. Esse fenômeno está fortemente ligado à expansão da soja durante as décadas de 1970 e 1980 e a uma conjuntura internacional favorável em termos dos preços das commodities, bem como de grandes investimentos públicos, incluindo melhoria dos transportes e subsídios à exportação (Conceição, 1984; Wesz Junior, 2014). No Rio Grande do Sul, um dos estados pioneiros no cultivo da soja, a superfície cultivada se concentrava nas áreas norte e 
noroeste de sua geografia, as quais apresentam condições climáticas e agronômicas favoráveis ao cultivo dessa oleaginosa. Todavia, nos anos seguintes expandiu-se para as demais regiões do país (Wesz Junior, 2014). Alguns dos fatores que podem ser citados como propulsores da expansão da soja para regiões que historicamente dedicavam-se à criação de gado são: ascensão do preço da soja, mercado externo favorável, altos subsídios à exportação, queda do preço da carne.

Encontramo-nos diante de fenômeno de grandes proporções e que não conhece solução de continuidade, senão justamente o contrário. Segundo fontes oficiais (Instituto Brasileiro de Geografia e Estatistica, 2016), em 2010 a área cultivada de soja no Rio Grande do Sul correspondia a 4.021.778 hectares. Todavia, apenas quatro anos depois constata-se uma expansão equivalente a 24\%, alcançando 4.990 .042 hectares. O alargamento do "território da soja" se dá em regiões até então inusitadas. Esse é justamente o caso das tradicionais áreas de pecuária extensiva (bovinos, ovinos e equinos) pertencentes ao chamado bioma Pampa. Estudo realizado por Kuplich et al. $(2018$, p. 83) indica que a área plantada com soja no bioma Pampa aumentou 188,5\% entre os anos 2000 e 2015 . Vale frisar que se trata de um ecossistema singular que ocupa 63\% do território do estado do Rio Grande do Sul e 2,07\% do território brasileiro, sendo formado por paisagens caracterizadas predominantemente por campo nativo e por uma grande diversidade de espécies animais e vegetais. No interior do Pampa encontra-se expressiva porção do Aquífero Guarani, o segundo ${ }^{1}$ maior manancial de água doce subterrânea do planeta. Dados do Ministério do Meio Ambiente ressalvam, entretanto, que o Pampa representa apenas 0,4\% da área do Brasil protegida por unidades de conservação, o que demonstra o seu elevado grau de vulnerabilidade em relação a outros ecossistemas do país.

Jaguarão é uma localidade situada no extremo meridional do Rio Grande do Sul, na fronteira com a República Oriental do Uruguai, estando totalmente inserida dentro do bioma Pampa. A pecuária extensiva (bovinos e ovinos) representa simultaneamente uma atividade econômica crucial e uma vocação tradicional dessa região sul-rio-grandense. O Ministério do Meio Ambiente (Brasil, 2016) descreve a importância da pecuária praticada em campos nativos desde os primórdios da colonização da emblemática região correspondente ao bioma Pampa:

Além de proporcionar resultados econômicos importantes, tem permitido a conservação dos campos e ensejado o desenvolvimento de uma cultura mestiça singular, de caráter transnacional representada pela figura do gaúcho (Brasil, 2016, p. 1).

A pecuária é uma atividade secularmente desenvolvida nessa região, sendo menos impactante (Brack, 2007) do que outros usos e práticas agrícolas. A importância da preservação dos campos nativos é descrita por Lanna (2010), que relata a importância do Pampa gaúcho sob diversas perspectivas: sob a óptica histórico-cultural, exaltando as origens da personificação do gaúcho; do ponto de vista paisagístico, ao constituir belas paisagens e cenários; sob a óptica ambiental, por apresentar grande diversidade de espécies. Sob a perspectiva econômica, não se pode minimizar a importância da excelência dos campos naturais para a produção de uma carne de qualidade alicerçada no sistema extensivo de produção, distinguindo-se frontalmente dos regimes intensivos baseados no confinamento dos animais e no uso de rações e concentrados.

Os benefícios que a preservação dos ecossistemas fornece são denominados de serviços ecossistêmicos. Ao estudar os serviços ecossistêmicos de campos naturais do bioma Pampa, Schossler (2016) menciona como primordiais a preservação do ambiente nativo, da qualidade da água, da beleza cênica, da biodiversidade, bem como o sequestro de carbono, que atenua o efeito das mudanças climáticas.

Contudo, nos últimos anos, Jaguarão experimentou a conversão de 37.000 ha em lavouras de soja, apesar de as características climáticas e do solo do município não serem

\footnotetext{
1 O Aquífero Guarani fica atrás somente do Aquífero Alter do Chão, situado na região Norte do país. Suas águas abrangem quatro países: Brasil $\left(840.000 \mathrm{~km}^{2}\right)$, Argentina $\left(225.500 \mathrm{~km}^{2}\right)$, Paraguai $\left(71.700 \mathrm{~km}^{2}\right)$ e Uruguai $\left(58.500 \mathrm{~km}^{2}\right)$.
} 
favoráveis ao cultivo da leguminosa em questão. Essa expansão está sendo capitaneada majoritariamente por agricultores originários, principalmente, da região noroeste do Rio Grande do Sul, já com tradição no plantio da soja, os quais passaram a arrendar e, em alguns casos, a comprar terras em Jaguarão. Essa migração ocorre em função da falta de áreas disponíveis para cultivo na região noroeste e pelo fato de os preços dos solos agrícolas, tanto para compra como para arrendamento, serem mais baixos em Jaguarão do que os praticados nas suas regiões de origem.

Esse fenômeno vem sendo valorado de diferentes formas pela população local, alternando pontos positivos e negativos dessa mudança. Entre os pontos positivos aventados, consta um suposto aumento das oportunidades de emprego, tanto diretos, como a contratação de trabalhadores rurais, como indiretos, a exemplo do aumento da demanda de serviços de borracharias e postos de gasolina. Outro aspecto seria a valorização das terras, visto que, em função do aumento da procura pelos sojicultores estrangeiros, elevaram-se os preços das terras. Alguns alegam que a soja promove ingresso de renda e impostos para o município, bem como a oportunidade de utilização da resteva (parte remanescente da lavoura, depois da colheita da soja), que acaba servindo de alimentação suplementar para o gado no período de inverno.

Entre os pontos negativos têm-se diversas alegações, como a interferência negativa nas demais criações e culturas por conta, dentre outros fatores, da aplicação intensiva de agrotóxicos que demandam as lavouras de soja. Por conta da deriva há prejuízos sobre o desenvolvimento dos pomares e das hortaliças, bem como à saúde das pessoas e do meio ambiente. Há relatos de contaminação, de impactos sobre a fauna e destruição de campo nativo, dado que o uso continuado de herbicidas promove o desaparecimento de espécies autóctones. Ao analisar o processo de expansão da soja no Uruguai, Morales (2013) constatou que houve o aumento da demanda pela terra e, com isso, a elevação do custo desse fator de produção naquele país, aspectos que ensejam a desterritorialização da produção familiar.

O reconhecimento acerca dos impactos deletérios da expansão da soja induz a que alguns atores locais cogitem a necessidade de criação de uma política pública e de um regramento específico que estabeleça limites para o plantio e, especialmente, para o uso de agrotóxicos ${ }^{2}$. Os objetivos deste estudo foram analisar os impactos socioambientais da expansão da soja e as diferentes percepções acerca da conveniência de criação de uma política pública orientada a regular o plantio de soja no município de Jaguarão/RS. $\mathrm{Na}$ análise que efetuamos foi utilizada a abordagem de narrativas de política pública, a qual foi concebida a partir de minucioso exame de depoimentos colhidos em entrevistas. Além dessa introdução, o artigo contempla outras quatro seções. A primeira delas descreve os procedimentos metodológicos adotados na investigação; a segunda inclui uma revisão teórica acerca do instrumental metodológico adotado. A terceira inclui a análise propriamente dita das entrevistas, utilizando a abordagem narrativa. Por fim, expomos, na quarta e última seção as considerações finais e alguns elementos conclusivos desta pesquisa.

\section{Procedimentos metodológicos}

Em relação aos procedimentos metodológicos, cabe destacar que se trata de um estudo de natureza qualitativa. Nesse sentido, trata-se de explorar elementos de natureza eminentemente subjetiva, o que não implica em renúncia ao rigor, fidedignidade e precisão na análise de dados e informações coletadas a campo. Para Silva \& Menezes (2005, p. 20), "o processo e seu significado são os focos principais de abordagem".

$O$ instrumento para coleta de dados foi a entrevista com roteiro semiestruturado. Primeiramente, foram realizadas três entrevistas piloto. A primeira delas ocorreu com um dos produtores rurais que demandam a criação da política; a segunda, com um produtor de soja, e a terceira, com um membro da administração pública municipal. Posteriormente,

\footnotetext{
2 Estudos indicam que a exposição ambiental aos herbicidas à base de glifosato causa danos à saúde humana, tais como a desregulação endócrina. Ver a propósito Mesnage et al. (2015).
} 
foram realizadas outras 27 entrevistas com roteiro semiestruturado. Os roteiros foram concebidos de forma distinta, de acordo com as características do grupo de atores, ainda que a essência das questões suscitadas seja a mesma.

A escolha dos entrevistados se deu graças às indicações dos extensionistas rurais do Escritório Municipal da Ascar-Emater, bem como de outros órgãos e representações locais. Essa metodologia de amostragem é denominada de "snowball" (bola de neve).

A execução da amostragem em bola de neve se constrói da seguinte maneira: para o pontapé inicial, lança-se mão de documentos e/ou informantes-chaves, nomeados como sementes, a fim de localizar algumas pessoas com o perfil necessário para a pesquisa, dentro da população geral. Isso acontece porque uma amostra probabilística inicial é impossível ou impraticável, e assim as sementes ajudam o pesquisador a iniciar seus contatos e a tatear o grupo a ser pesquisado. Em seguida, solicita-se que as pessoas indicadas pelas sementes indiquem novos contatos com as características desejadas, a partir de sua própria rede pessoal, e assim sucessivamente e, dessa forma, o quadro de amostragem pode crescer a cada entrevista, caso seja do interesse do pesquisador (Vinuto, 2014, p. 203).

Foi solicitada a indicação de quatro grupos de produtores: que plantam soja e vieram de outros municípios, produtores que plantam soja e são de Jaguarão, pecuaristas e agricultores de Jaguarão que não plantam soja e produtores que arrendam área para o plantio da soja, procurando assim abranger a diversidade de atores implicados. Conforme o trabalho de campo foi sendo desenvolvido, recebemos outras indicações de entrevistados que se mostraram cruciais para que fosse construído um quadro que contemplasse as mais distintas valorações sobre as questões em análise. Ao final, o processo de amostragem resultou numa composição que incluiu:

a) sete agricultores que plantam soja em Jaguarão, os quais, em sua plenitude, não são naturais do município. $O$ conjunto de indivíduos nessa condição em Jaguarão equivale a um total de 95 produtores, segundo indicações do escritório local da Ascar-Emater.

b) doze agricultores e pecuaristas nativos. Segundo dados da Ascar-Emater local, existem 300 produtores locais nessa condição em Jaguarão.

c) dois produtores nativos de Jaguarão que também plantam soja.

d) dois extensionistas rurais do município e três representantes de entidades ligadas ao meio rural, incluindo o Sindicato dos Trabalhadores Rurais e o Sindicato Rural de Jaguarão, totalizando, nesse subgrupo, cinco entrevistas;

e) uma moradora da cidade, que no decorrer da pesquisa foi indicada por um dos entrevistados como exemplo de ator local que recorreu ao poder público, relatando impactos decorrentes da expansão da soja no município.

As entrevistas foram feitas até alcançar o ponto de saturação, momento em que começou a haver repetição nas respostas e recorrência na argumentação dos atores em torno das questões propostas no roteiro. Através das entrevistas, "o pesquisador busca obter informes contidos na fala dos atores sociais" (Minayo, 2001, p. 57). Com efeito, na escolha dos entrevistados, buscou-se abranger as diferentes perspectivas dos atores locais sobre a temática em tela.

\section{Abordagem narrativa de política pública}

Existe certa controvérsia acerca do conceito de política pública. Alguns autores (Lopes, 2015) consideram que, como tal, estão incluídos temas sobre os quais o Estado deixa de atuar. Para Souza (2006), política pública é o campo do conhecimento que procura, simultaneamente, pôr o governo em ação, avaliar a ação, bem como sugerir alterações consideradas necessárias. Uma política pública abrange mais do que uma decisão. Nesse sentido, "[...] embora uma política pública implique decisão política, nem toda decisão política chega a constituir uma política pública" (Rua, 2013, p. 8). 
A análise de políticas públicas conta com várias abordagens teóricas. Para Lessa et al. (2015, p. 195), “a análise se preocupa com o processo de construção da política pública, principalmente, no que se refere à definição da agenda governamental". Uma das abordagens teóricas para a análise de políticas públicas é a abordagem narrativa. O estudo das narrativas permite compreender como os atores arquitetam sua relação com o tema por meio da interpretação de como eles elaboram suas narrativas sobre o assunto, bem como os argumentos postos em questão.

O reconhecimento do problema e as percepções dos atores envolvidos no evento irão definir os elementos iniciais através da elaboração de explicações e narrações (Muller \& Surel, 2002). Segundo Grisa (2012, p. 51) "as narrativas podem ser compreendidas como argumentações, consideradas 'verdades', que tentam influenciar o decurso de uma política pública" (destacado no original).

Destarte, Muller \& Surel (2002) indicam que:

A produção de discursos concorrentes sobre um mesmo fenômeno implica por isso mesmo uma competição sobre a qualificação do problema sob um ângulo particular, que implica a seleção das causas consideradas pertinentes, a formulação de uma explicação conforme as «visões de mundo» dos atores envolvidos e, enfim, a elaboração de propostas de resolução do problema (Muller \& Surel, 2002, p. 57; destacado no original).

Lopes (2015) esclarece que a análise de narrativa política exibe os fatores subentendidos da política, como ideias, interesses e valores. Inicia-se com a ênfase no problema, sendo elaboradas suas respectivas causas, propostas de soluções bem como suas respectivas consequências. Caso a solução não seja executada, emerge um "cenário apocalíptico" (Grisa, 2012, p. 51). Também ocorre uma relação de poder nas narrativas: uma narrativa pode ser considerada influente, encobrindo as demais. Segundo Grisa, "quando uma narrativa se torna hegemônica e institucionaliza suas ideias, ela altera as relações de força concedendo mais poder ao grupo de atores portador da nova narrativa, enquanto a influência dos antecessores está em declínio" (Grisa, 2012, p. 52).

Grisa (2012) relata ainda que não se deve analisar as narrativas de forma isolada: sua força só pode ser medida se forem considerados outros atributos do contexto em que ela se insere. Nesse mesmo sentido, Lessa et al. (2015, p. 195) afirmam que "as políticas devem ser compreendidas no contexto de sua execução e que a sua implementação diz respeito às pessoas que de fato a implementam".

Em seu estudo sobre uso de narrativas em pesquisas organizacionais, Czarniawska (2000) propõe caminhos para a análise de narrativas nos estudos de ciências sociais. Em primeiro lugar, há que observar como as histórias estão sendo feitas, angariar as histórias e provocar a narrativa; em segundo lugar, interpretar, analisar e desconstruir as histórias e, por fim, montar sua própria história e contrapor ou aproximar com outras histórias, contribuindo, assim, com o campo de pesquisa sobre o assunto estudado.

Por seu turno, Radaelli (2000) apresenta as características essenciais de narrativas de políticas públicas. Para esse autor, as narrativas representam a forma que assumem os elementos cognitivos ligados a uma política pública, sendo que a ordem sequencial dos eventos é uma propriedade fundamental das narrativas. Tal autor esclarece que há três maneiras de empregar as narrativas: como uma ferramenta para os profissionais; como uma epistemologia e como um objeto. Para Radaelli, transformada em uma forma de comunicação clara e conseguindo transmitir ideias com convicção, a narrativa dominante é componente essencial da estrutura cognitiva de uma política pública.

A abordagem narrativa, neste estudo, busca identificar, portanto, as especificidades das narrativas, as semelhanças, os conflitos explícitos e implícitos, bem como o apelo presente nos argumentos usados pelos atores envolvidos com a temática. 


\section{A expansão da soja no município de Jaguarão/RS}

Seguindo os passos adotados por Bittencourt \& Fontenelle (2013), primeiramente buscou-se a ideia geral, as "macronarrativas", em relação à criação de uma política pública para regulamentar o plantio de soja no município de Jaguarão/RS. Os autores consideram "a diferenciação entre macro e micronarrativas como meio para construir diálogo entre as diferentes histórias" (Bittencourt \& Fontenelle, 2013, p. 12). Em seguida parte-se para a análise do que os autores chamam de micronarrativas, que seria "o olhar mais atento às narrativas sobre eventos específicos" (Bittencourt \& Fontenelle, 2013, p. 12).

A ideia geral, macronarrativa, exposta pelos entrevistados, é apresentada nos seguintes termos: o município de Jaguarão, historicamente, teve como atividades principais a bovinocultura de corte e a ovinocultura, e, em menor número, a presença de lavouras de arroz irrigado. As áreas destinadas à pecuária, em sua esmagadora maioria, eram formadas por campo nativo. Nos últimos anos, agricultores que vieram do norte e noroeste do estado do RS, motivados pela escassez de terras e pelos altos custos de arrendamento em seus locais de origem, deslocam-se para o extremo sul do estado, atraídos, justamente, pelos baixos preços das terras, incluindo, precisamente, o caso de Jaguarão.

Desse modo dá-se a expansão das áreas cultivadas com soja no município de Jaguarão, que até então ocorria de forma muito restrita e pontual. Essa situação ocasionou a ocupação de áreas antes destinadas à pecuária com lavouras de soja. Com isso, houve um aumento significativo no uso de agrotóxicos e adubos químicos, da mecanização dos solos, uma diminuição do rebanho bovino e ovino e danos recorrentes nas estradas rurais pelo tráfego intenso de caminhões pesados utilizados no transporte da colheita da soja.

Há também relatos de produtores preocupados com a produção de hortaliças e pomares para o autoconsumo ou para a venda devido ao uso de agrotóxicos em áreas próximas, que contaminam a sua produção em função da deriva nas aplicações realizadas pelos sojicultores. Atualmente o marco legal que regulamenta a aplicação de agrotóxicos é a lei complementar $n^{\circ} 2$, de 2002. Todavia, segundo relatos dos entrevistados, tal instrumento é superficial, desatualizado e incompatível com os efeitos da dinâmica engendrada pela soja. Por esse motivo os órgãos municipais de fiscalização utilizam a lei federal $n^{\circ} 7.802$, de 1989, denominada Lei dos Agrotóxicos, e com relação à aplicação aérea de agrotóxicos, a instrução normativa $n^{\circ}$ 2, do ano de 2008, do Ministério da Agricultura, Pecuária e Meio ambiente, que prevê, dentre outras coisas, uma distância mínima, na aplicação, de $500 \mathrm{~m}$ de povoações e $250 \mathrm{~m}$ de moradias isoladas e agrupamentos de animais.

Outro aspecto que está ligado à macronarrativa da soja tem a ver com o fato de que 90\% dos produtores são de fora de Jaguarão, cristalizando, no imaginário local, a imagem do indivíduo aventureiro, que vem de longe para impor sua visão de mundo e fazer valer seus interesses pessoais, centrados, obviamente, no lucro a ser obtido em curto prazo com o plantio de uma commodity. Ao estudar sobre o avanço da soja em áreas do Pampa, Pizzato (2013) identificou esse mesmo cenário de "estrangeirização" ligado a essa cultura.

Frente a essa situação, um grupo de produtores locais que não plantam soja, incluindo pecuaristas familiares, olericultores e moradores da cidade, residentes próximos às áreas de lavoura, posiciona-se no sentido de exigir a criação de uma política ou de instrumentos que regulem o plantio da soja em nível local, mormente no que toca à questão da pulverização de agrotóxicos, do uso e conservação das estradas. Em suas falas, buscam convencer o poder público municipal e o restante da população a respeito dessa necessidade.

Um desses agricultores salienta que:

Já nos reunimos com o prefeito e por diversas vezes expomos nas reuniões do conselho municipal de Desenvolvimento Rural os problemas que estamos enfrentando com a expansão da soja aqui em Jaguarão e solicitamos a criação de uma política que regulamente o uso de agrotóxicos na soja, a expansão das áreas plantadas e o uso das estradas para o transporte.

Outro depoente relata o descontentamento dos olericultores com a situação: “Todos os pequenos produtores que plantam hortaliças reclamam, até porque querem plantar 
produto orgânico e não conseguem porque, de alguma forma, interfere com os produtos". Essa narrativa é composta por eventos que descrevem como a introdução da soja rompe com o equilíbrio que havia, até então, com os cultivos e criações integrados ao território, trazendo à tona a necessidade de que algo seja feito a respeito. São apontadas consequências negativas do ponto de vista ambiental, estrutural e social, conforme o relato de outro produtor local:

A parte ruim é a utilização de agrotóxicos. Isso aí é terrível, terrível, no meu ponto de vista. Eu quero ver o que vai ser daqui a alguns anos mais, do jeito que tão largando veneno em cima da cabeça da gente eu não sei sinceramente o que vai ser daqui uns anos mais. Esses campos, mesmo no momento que parar de plantar soja, vai virar tudo deserto porque não vem mais nada. O uso de herbicida principalmente está terminando com o nosso campo nativo.

Portanto o desafio seria justamente encontrar meios de enfrentamento aos deletérios efeitos da expansão da soja. O processo de formulação de política pública passa pelas demandas. No caso em tela de juízo, a demanda pode ser considerada nova (Rua, 2013), inédita no contexto apresentado.

Os sojicultores, por sua vez, defendem a ideia da soja como sinônimo de desenvolvimento e modernidade, ressaltando a importância da renda gerada para o município com a expansão das áreas cultivadas com essa cultura. Um dos sojicultores argumenta que "com a introdução e expansão da soja aqui no município houve o aumento da renda, da arrecadação, o desenvolvimento do município". Outro descreve que "o que tem de positivo é que desde que estamos aqui vemos que a cidade melhorou muito em termos de renda".

A respeito dessa narrativa é importante ressaltar que por diversas vezes, durante a realização da pesquisa, estabelecemos contato com a Secretaria Municipal da Fazenda. Nosso intuito era justamente apurar números que indicassem ou estimassem a contribuição da soja para a economia municipal. Em outras palavras, buscamos captar algum indício sobre eventual formação de riqueza produzida pela soja, no âmbito local, nos últimos anos. Lamentavelmente, fomos informados de que esse dado inexiste na contabilidade municipal. A título de exemplo, o chamado rateio do Imposto sobre Circulação de Mercadorias e Serviços (ICMS) é feito a partir de uma série de critérios definidos em lei. Todavia, o fator de maior peso é a variação medida do Valor Adicionado Fiscal, que responde por $75 \%$ na composição do índice, o qual é calculado pela diferença entre vendas e compras realizadas nas empresas do município. Todavia, como ficou demonstrado ao longo da pesquisa, a esmagadora proporção das operações de compras de insumos ligados à soja ocorre fora de Jaguarão.

Em relação à análise mais minuciosa de partes das narrativas, as chamadas micronarrativas, podem ser extraídas várias observações. Um dos entrevistados nativos, que é olericultor, aponta um cenário apocalíptico caso a política não seja criada:

Já estamos vendo o fim da pecuária familiar no município, perda de elementos relacionados à identidade cultural do município que é ligada à imagem do gaúcho, a contaminação dos pomares e hortas, além dos danos à saúde da população - pelo uso de agrotóxicos através da aviação agrícola, que pulveriza e contamina a produção em função da deriva - e destruição das estadas, devido à circulação de caminhão do tipo bitrem para o transporte da soja. (Destaques nossos)

Os sojicultores relatam que o uso de agrotóxicos por meio da aviação agrícola ${ }^{3}$ já era praticado anteriormente pelos arrozeiros, antes da chegada dos sojicultores a Jaguarão. Segundo as palavras de um de nossos entrevistados, "os arrozeiros já usavam a aviação para

\footnotetext{
${ }^{3}$ Alguns municípios possuem legislação própria que regulamenta o uso da aviação aérea, como é o caso de Pelotas/RS, distante $140 \mathrm{~km}$ de Jaguarão. Nessa localidade, devido a ocorrências registradas por produtores atingidos em suas lavouras e pastagens pela pulverização de agrotóxicos, a aplicação aérea fica restrita a áreas de exclusão, as quais foram definidas através de laudo emitido pela Secretaria Estadual do Meio Ambiente.
} 
aplicação antes da introdução da soja e o uso de caminhões pesados também é feito pelos pecuaristas para o transporte do gado". Acrescentam ainda que os sojicultores não realizam o transporte da produção em dias de chuva, o que gera sempre maiores danos às estradas rurais. Todavia, ainda segundo sua fala, o pecuarista faz o transporte em qualquer situação climática, mesmo sob condições de chuva. O que vemos estampado nesses depoimentos é uma tentativa de eximir-se dos problemas causados pela soja e por ações lesivas praticadas por pessoas que vêm de fora. Uma interpretação possível seria justamente considerar que tais alegações se inscrevem na tendência a culpar "os de fora" diante de prejuízos gerados localmente. Não obstante, há outros elementos que devem ser trazidos à discussão. Sobre essa situação, Lopes (2015, p. 13) esclarece que "muitas vezes, histórias com 'diferentes versões' são contadas na arena decisória, por diferentes grupos, que pretendem obter adesões para que se mude ou se preserve um determinado status quo".

Sobre os problemas e potencialidades da produção da soja no município, alguns dos produtores nativos entrevistados questionam eventuais benefícios e pontos positivos, a exemplo dos impostos gerados para o município: "Não sei se o livro de produtor rural dos sojicultores está cadastrado em Jaguarão ou no município de origem deles". A geração de empregos também é questionada: "A soja, por causa dessas máquinas, hoje é pouca gente, em relação às áreas, são áreas muito grandes e trabalham com pouca gente". Apontam assim o predomínio claro de aspectos negativos em relação a eventuais benefícios ou aspectos positivos.

A respeito desses argumentos cabem aqui algumas considerações. Alguns produtores nativos entrevistados questionam a situação dos livros de produtor rural dos sojicultores. Não afirmam com certeza, mas o fato de questionar está de acordo com o que afirma Grisa (2012, p. 51): "Mesmo quando sua veracidade está em questão, as narrativas visam que os receptores a interiorizem e tomem uma atitude em relação ao problema". Ou seja, constroem uma narrativa agregando dúvidas e desconfiança frente ao argumento dos ganhos ou eventuais benefícios advindos da entrada da soja. Sobre a questão da geração da riqueza no âmbito local, a fala dos sojicultores oculta grandes imprecisões.

A forma de produzir soja se baseia em operações comerciais realizadas quase totalmente descoladas do âmbito local. A contratação de crédito de custeio, a compra de insumos (adubos químicos, agrotóxicos etc.) e outras operações ligadas a essa cultura se dão alhures. Muitos sojicultores mantêm seus vínculos com seus locais de origem no que tange à aquisição de bens e serviços ligados à soja. Essa faceta do processo depõe contra o argumento central desses produtores frente aos possíveis benefícios dessa commodity do ponto de vista tributário. A soja é uma atividade que goza, no Brasil, de um tratamento fiscal diferenciado graças ao advento da lei de desonerações das exportações, mais conhecida como "Lei Kandir"4. Assim sendo, a geração de riqueza pela aplicação de impostos é praticamente inexistente.

Os produtores entrevistados que cederam suas áreas para o plantio da soja, em sua maioria, são produtores com mais de 50 anos. A decisão de arrendar se dá em virtude dos preços mais altos oferecidos pelos sojicultores, se comparados com os preços praticados no âmbito da pecuária. Além disso, muitas dessas propriedades não têm perspectiva de sucessão. Em estudo que objetivou analisar se o uso da terra no bioma Pampa estava proporcionando a conservação ou ameaça ao bioma, Echer et al. (2016) constataram que: "A soja promove um ciclo especulativo nos preços das áreas, estimulando a venda das propriedades e o abandono de ofícios e atividades ancestrais nos espaços rurais" (Echer et al., 2016, p. 11).

Os sojicultores não mencionam, em suas falas, os impactos ambientais como pontos negativos. Trata-se de temas que geram ampla controvérsia. Para contrapor-se a tais argumentos os sojicultores buscam associar a soja ao desenvolvimento econômico dessa

\footnotetext{
${ }^{4}$ A lei complementar no 87, mais conhecida como "Lei Kandir", que entrou em vigor em 13 de setembro de 1996, dispõe sobre o imposto dos estados e do Distrito Federal nas operações relativas à circulação de mercadorias e serviços (ICMS). Ela isenta do recolhimento do Imposto de Circulação de Mercadorias e Serviços (ICMS) os bens e serviços destinados à exportação. A lei tem esse nome em virtude do seu autor, o ex-deputado federal Antônio Kandir. Estudo realizado por Marques Júnior \& Oliveira (2014) exalta os impactos negativos dessa lei sobre a arrecadação do ICMS.
} 
parte do território sul-rio-grandense, bem como enquanto solução para a estagnação de uma região tida como arcaica e atrasada. Grisa (2012, p. 52) faz uma ponderação interessante a respeito do "não dito" em narrativas: "Também é importante considerar a narrativa pelo que ela não diz, ou seja, o poder que tem de reduzir ao silêncio as narrativas concorrentes".

A respeito da criação da política pública municipal para regulamentar as questões apresentadas em relação ao plantio da soja no município, alguns olericultores apresentaram seu pleito e justificativas nas reuniões do Conselho Municipal de Desenvolvimento Rural e em negociações e tratativas realizadas junto ao poder público municipal. A maior parte dos entrevistados, no entanto, relata não ter um conhecimento amplo sobre tais encaminhamentos. A baixa capacidade de articulação e de protagonismo no encaminhamento de suas pautas e demandas parece refletir a natureza de regiões rurais marcadas pelo individualismo e insulamento dos atores sociais.

Um dos representantes do poder público municipal entrevistado relatou que essa regulamentação já esteve em debate, havendo sido realizadas reuniões com produtores e com vereadores do município. Segundo ele, "as discussões ainda estão em fase inicial, por ser uma situação nova para o município, e precisa de aprofundamento nos debates com a população". Reconhece, não obstante, a relevância do assunto, bem como que advirá, futuramente, algum tipo de regulamentação, principalmente em relação à exclusão de áreas de aviação agrícola e ao uso e conservação das estradas rurais.

Sobre os benefícios da criação da política, os entrevistados reconhecem a importância da produção de alimentos "mais limpos", ou seja, sem o uso de agrotóxicos, e que essa regulamentação viria no sentido de contribuir para isso. Os benefícios gerados pela regulamentação do tráfego nas estradas rurais também são consenso entre os entrevistados, apesar de eles relatarem visões opostas em relação ao plantio da soja no município.

Nas narrativas colhidas entre atores sociais nativos sobressaem diversos elementos expondo o pesar com progressivo declínio da pecuária familiar em meio à expansão da soja. Um dos aspectos que questionamos nas entrevistas junto aos produtores nativos era no sentido de saber se teriam interesse em plantar soja. Todas as respostas foram contrárias. Dentre os motivos expostos sobressaem a aversão ao elevado uso de agrotóxicos que a cultura exige, a preocupação com a saúde, a dependência ao mercado. A tradição e o gosto pela pecuária se opõem ao "mundo da soja". A criação de gado é uma atividade secular e um dos signos de identidade cultural do gaúcho. Inclui a paisagem pampiana e um estilo de vida rural, os quais, conjuntamente, forjaram a própria história local e regional. No extremo oposto, ou seja, nas narrativas dos sojicultores oriundos, quase exclusivamente, da zona setentrional do Rio Grande do Sul, esses elementos nem sequer são mencionados. Tais atores sociais se autointitulam portadores de uma modernidade centrada em novas tecnologias e num modo de produzir que se choca com o tradicionalismo local.

Em estudo realizado em outra região do Pampa (Dom Pedrito), com o objetivo de compreender como os pecuaristas relacionam-se com o avanço da soja, Moreira et al. (2018) também identificaram o mesmo antagonismo discursivo: de um lado, os que percebem a expansão da soja como influência negativa para a pecuária; de outro, os que veem a expansão da soja de forma positiva, benéfica para a pecuária. Mas há ainda um terceiro grupo que percebe tanto aspectos positivos como negativos na expansão da oleaginosa.

\section{Considerações finais}

Este trabalho analisou as demandas ligadas à criação de uma política pública para regulamentar o plantio de soja no município de Jaguarão/RS tendo por base a abordagem narrativa. A concepção da abordagem narrativa é no sentido de averiguar a história que os atores constroem para sustentar a necessidade de mudanças e/ou de erigir um novo marco de regulação para matérias marcadas pela controvérsia.

Eles detectam um problema comum e desenham estratégias argumentais que, em boa medida, apontam para um cenário desfavorável, caso nada seja feito no sentido de 
enfrentá-lo. A análise de políticas públicas resulta no esforço de entendimento acerca do caminho a ser percorrido até a criação da política, a identificação consistente do problema para o qual a política pública é desenhada, bem como o papel dos atores sociais envolvidos.

As narrativas nos permitem identificar elementos importantes do debate, que muitas vezes não são ditos ou explicitados com a devida clareza. Eles estão presentes nas ocultações instintivas, irrefletidas ou mesmo intencionais. As valorações em torno da expansão da soja e dos seus impactos socioambientais no município de Jaguarão ensejam visões claramente antagônicas. A mesma orientação se dá no que tange à necessidade de criação de uma política pública ou de instrumentos específicos de regulação. De um lado, os que falam que é imperativo criar algum mecanismo de controle, de outro, um grupo que se considera portador de uma modernidade que traz dinamismo à região.

Entre ambas as estruturas narrativas se inserem o poder público municipal e as demais instâncias mediadoras, as quais se posicionam de forma claramente ambígua, apesar de reconhecerem a gravidade do problema. Nem mesmo os benefícios fiscais foram evidenciados enquanto argumento capaz de contrapor os aspectos negativos. Por meio das narrativas revela-se também a necessidade de aprofundamento de um debate dialógico que hodiernamente se dá de forma difusa e pouco produtiva no sentido de encaminhar soluções possíveis que atendam à maior parte da população local.

Ao realizar este estudo buscamos contribuir nesse processo, especialmente diante da necessidade de trazer à tona uma questão que, decididamente, extrapola os marcos territoriais do município de Jaguarão. Em tom absolutamente profético, um estudioso do fenômeno de sojicização da realidade agrária e rural do Brasil vaticinou: "A soja tem uma dinâmica semelhante à do garimpo. Quando é encontrado ouro em algum lugar todos vão para lá. Legalmente e ilegalmente" (Vankrunkelsven, 2014, p. 128). A expansão da soja que atingiu Jaguarão na última década, a exemplo do que ocorre em todo o bioma Pampa, é fonte de preocupação, servindo de exemplo ilustrativo de uma tendência que, ao que tudo indica, se impõe de forma insofismável.

\section{AGRADECIMENTOS}

Este trabalho não poderia ter sido realizado sem o apoio do Conselho Nacional de Desenvolvimento Científico e Tecnológico através da concessão de bolsa produtividade ao segundo autor (processo $n^{\circ}$ 305086/2018-9), bem como à Coordenação de Aperfeiçoamento de Pessoal de Nível Superior, pela concessão de Bolsa de Professor Visitante Sênior (PRINT-CAPES PROGRAM) ao segundo autor (processo n 88887.363956/2019-00), a qual viabilizou missão científica (2019-2020) junto ao "Instituto de Estudios Sociales Avanzados" (Córdoba), ligado ao "Consejo Superior de Investigaciones Científicas de Espanha", a quem agradece a acolhida.

\section{Referências}

Bittencourt, L. N., \& Fontenelle, I. A. (2013). Estudo de políticas públicas a partir de narrativas: o caso do processo de elaboração do Programa de Revitalização e Desenvolvimento da Região Central Histórica de Santos. Cadernos Gestão Pública e Cidadania, 19(62). Recuperado em 5 de agosto de 2016, de http://bibliotecadigital.fgv.br/ojs/index.php/cgpc/article/viewFile/8635/13463

Brack, P. (2007). O pampa gaúcho é alvo de biopirataria, denuncia ambientalista. Revista Instituto Humanitas Unisinos, 247, 13-16. Recuperado em 12 de janeiro de 2017, de http://www.biodiversidade.rs.gov.br/arquivos/1199813241IHU_ON_LINE_dez1._2007_119730913 7.15pdf.pdf

Brasil. Ministério do Meio Ambiente - MMA. (2016). Pampa. Recuperado em 9 de julho de 2016, de http://www.mma.gov.br/biomas/pampa

Brum, A. (1987). O desenvolvimento econômico brasileiro (8. ed.). Rio de Janeiro: Vozes.

Conceição, O. A. C. (1984). A expansão da soja no Rio Grande do Sul: 1950-75. Porto Alegre: Fundação de Economia e Estatística. Recuperado em 9 de julho de 2016, de http://cdn.fee.tche.br/digitalizacao/teses-fee/expansao-soja-rio-grande-do-sul-teses-6/expansaosoja-rio-grande-do-sul-teses-6-texto.pdf.pdf 
Conterato, M. A. (2004). A mercantilização da agricultura familiar do Alto Uruguai/RS: um estudo de caso no município de Três Palmeiras (Dissertação de mestrado). Faculdade de Ciências Econômicas, Universidade Federal do Rio Grande do Sul, Porto Alegre.

Czarniawska, B. (2000). The uses of narrative in Organization Research (GRI Report, No. 2000:5). Gothenburg: Gothenburg Research Institute, School of Economics and Commercial Law, Göteborg University. Recuperado em 5 de agosto de 2016, de https://gupea.ub.gu.se/bitstream/2077/2997/1/GRI-rapport-2000-5.pdf

Echer, R., Weykamp da Cruz, J. A., Costa Estrela, C., Moreira, M., \& Gravato, F. (2016). Usos da terra e ameaças para a conservação da biodiversidade no bioma Pampa, Rio Grande do Sul. Revista Thema, 12(2), 4-13.

Ellis, F. (1999). Rural livelihood diversity in developing oping countries evidence and policy implications. Natural Resource Perspectives, 40.

Grisa, C. (2012). Políticas públicas para a agricultura familiar no Brasil: produção e institucionalização das ideias (Tese de doutorado). Programa de Pós-graduação de Ciências Sociais em Desenvolvimento, Agricultura e Sociedade, Universidade Federal Rural do Rio de Janeiro, Rio de Janeiro.

Instituto Brasileiro de Geografia e Estatistica - IBGE. (2016) Perfil dos Estados. Recuperado em 26 de julho de 2016, de http://www.ibge.gov.br/estadosat/perfil. php?lang=\&sigla=rs

Kuplich, T. M., Capoane, V., \& Costa, L. F. F. (2018). O avanço da soja no Bioma Pampa. Boletim Geográfico do Rio Grande do Sul, (31), 83-100.

Lanna, A. E. (2010). O bioma pampa em risco? A plantação de pínus e eucaliptos. Revista Instituto Humanitas Unisinos, (247), 17-21. Recuperado em 12 de janeiro de 2017, de http://www.biodiversidade.rs.gov.br/arquivos/1199813241IHU_ON_LINE_dez1._2007 119730913 7.15pdf.pdf

Lessa, G., Kuehlkamp, V. M., Erdmann, A. L., \& Andrade, S. R. (2015). Análise de políticas públicas de saúde: revisão narrativa. Cogitare Enfermagem, 20(1), 191-197. http://dx.doi.org/10.5380/ce.v20i1.36885

Lopes, B. R. V. (2015). Função da "análise de narrativa política": para se entender (e problematizar) mudanças institucionais e de paradigmas políticos. São Paulo: Departamento de Ciência Política, Faculdade de Filosofia, Letras e Ciência Humanas, Universidade de São Paulo.

Marques Júnior, L. S., \& Oliveira, C. A. (2014). As elasticidades de curso e longo prazo do ICMS no RS (Textos para Discussão, No. 117). Porto Alegre: FEE.

Mesnage, R., Defarge, N., Spiroux de Vendômois, J., \& Séralini, G. E. (2015). Potential toxic effects of glyphosate and its commercial formulations below regulatory limits. Food and Chemical Toxicology, 84, 133.

Minayo, M. C. S. (Ed.). (2001). Pesquisa social: teoria, método e criatividade (18. ed.). Petrópolis: Vozes.

Morales, S. (2013). La "sojización" y la tierra en disputa: desarrollo del capitalismo agrario en Uruguay. Revista NERA, 16(23).

Moreira, J. G., Matte, A., \& Conterato, M. A. (2018). “E esses campo são bom”: a percepção dos pecuaristas sobre a atividade pecuária diante do crescimento das lavouras de soja no bioma Pampa. In Anais do VI Simpósio de Ciência do Agronegócio.

Muller, P., \& Surel, Y. (2002). A análise das políticas públicas (A. Bavaresco \& A. R. Ferraro, Trad.). Pelotas: Educat.

Niederle, P. A. (2007). Mercantilização, estilos de agricultura e estratégias reprodutivas dos agricultores familiares de Salvador das Missões, RS (Dissertação de mestrado). Faculdade de Ciências Econômicas, Universidade Federal do Rio Grande do Sul, Porto Alegre.

Pizzato, F. (2013). Pampa gaúcho: causas e consequências do expressivo aumento das áreas de soja (Dissertação de mestrado). Instituto de Geociências, Universidade Federal do Rio Grande do Sul, Porto Alegre.

Radaelli, C. (2000). Logiques de pouvoirs et récits dans les politiques publiques de l'Union Européene. Revue Française de Science Politique, 50(2), 255-275. http://dx.doi.org/10.3406/rfsp.2000.395467

Ribeiro, C. R. (2009). Estudo do modo de vida dos pecuaristas familiares da Região da Campanha do Rio Grande do Sul (Tese de doutorado). Faculdade de Ciências Econômicas, Universidade Federal do Rio Grande do Sul, Porto Alegre.

Rua, M. G. (2013). Para aprender políticas públicas (Vol. 1, Conceitos e teorias). IGPEP. Recuperado em 2 de agosto de 2016, de http://igepp.com.br/uploads/ebook/ebookpara_aprender_politicas_publicas2013.pdf 
Sacco dos Anjos, F. S. (2003). Agricultura familiar, pluriatividade e desenvolvimento rural no sul do Brasil. Pelotas: Ed. UFPEL.

Sacco dos Anjos, F. S., \& Caldas, N. (2007). Sob o efeito da desagrarização: agricultura familiar e pluriatividade no Rio Grande do Sul. Estudos Sociedade e Agricultura, 15(2), 310-339.

Sacco dos Anjos, F. S., Caldas, N. V., \& Hirai, W. G. (2010). Mudanças nas práticas de autoconsumo dos produtores familiares: estudo de caso no sul do Brasil. Agroalimentaria, 16(30), 115-125.

Schossler, D. S. (2016). Identificação de Serviços Ecossistêmicos de Campos Naturais no Bioma Pampa e Valoração do estoque de carbono do solo utilizando a Metodologia TESSA (Dissertação de mestrado). Programa de Pós-graduação em Manejo e Conservação do Solo da Água, Universidade Federal de Pelotas, Pelotas.

Silva, E. L., \& Menezes, E. M. (2005). Metodologia da pesquisa e elaboração de dissertação (4. ed. rev. atual.). Florianópolis: UFSC.

Souza, C. (2006). Políticas públicas: uma revisão da literatura. Sociologias, 8(16), 20-45. http://dx.doi.org/10.1590/S1517-45222006000200003

Vankrunkelsven, L. (2014). Soja: tesouro ou tesoura? Curitiba: L.F. Editora e Impressos.

Vinuto, J. (2014). A amostragem bola de neve na pesquisa qualitativa: um debate em aberto. Temáticas, 22(44), 203-220.

Wesz Junior, V. J. (2014). O mercado da soja e as relações de troca entre produtores rurais e empresas no Sudeste de Mato Grosso (Brasil) (Tese de doutorado). Instituto de Ciências Humanas e Sociais, Universidade Federal Rural do Rio de Janeiro, Rio de Janeiro. Recuperado em 21 de julho de 2016, de http://r1.ufrrj.br/cpda/wpcontent/uploads/2014/10/Wesz_Jr_Tese_2014-1.pdf 